\title{
Dual Catalyst Control in the Enantioselective Intramolecular Morita-Baylis-Hillman Reaction
}

\author{
Carrie E. Aroyan, Melissa M. Vasbinder and Scott J. Miller* \\ Department of Chemistry, Merkert Chemistry Center, Boston College, Chestnut Hill, \\ Massachusetts02467-3860Email: scott.miller.1@bc.edu
}

\section{Supporting Information}

General Procedures. Proton NMR spectra were recorded on a Varian $400 \mathrm{MHz}$ spectrometer. Proton chemical shifts are reported in $\mathrm{ppm}(\delta)$ relative to internal tetramethylsilane (TMS, $\delta 0.0 \mathrm{ppm}$ ) or with the solvent reference relative to TMS employed as the internal standard $\left(\mathrm{CDCl}_{3}, \delta 7.26 \mathrm{ppm} ; \mathrm{d}_{6}-\mathrm{DMSO}, \delta 2.50 \mathrm{ppm} ; \mathrm{CD}_{3} \mathrm{OD}\right.$, $\delta 3.31 \mathrm{ppm} ; \mathrm{D}_{2} \mathrm{O}, \delta 4.79 \mathrm{ppm}$ ). Data are reported as follows: chemical shift (multiplicity [singlet (s), doublet (d), triplet (t), quartet (q), and multiplet (m)], coupling constants $[\mathrm{Hz}]$, integration). Carbon NMR spectra were recorded on a Varian $400(100 \mathrm{MHz})$ spectrometer with complete proton decoupling. Carbon chemical shifts are reported in $\mathrm{ppm}(\delta)$ relative to TMS with the respective solvent resonance as the internal standard $\left(\mathrm{CDCl}_{3}, \delta 77.0 \mathrm{ppm}\right)$. Infrared spectra were obtained on a Perkin-Elmer Spectrum 1000 spectrometer. Analytical thin-layer chromatography (TLC) was performed using Silica Gel $60 \AA$ F254 precoated plates $\left(0.25 \mathrm{~mm}\right.$ thickness). TLC $\mathrm{R}_{f}$ values are reported. Visualization was accomplished by irradiation with a UV lamp and/or staining with $\mathrm{KMnO}_{4}$ or cerium ammonium molybdenate (CAM) solutions. Flash column chromatography was performed using Silica Gel 60A $(32-63 \mu \mathrm{m}){ }^{1}$ Optical rotations were recorded on a Rudolf Research Analytical Autopol IV Automatic polarimeter at the sodium D line (path length $50 \mathrm{~mm}$ ). High resolution mass spectra were obtained at the Mass Spectrometry Facility of either Boston College (Chestnut Hill, MA) or the University of Illinois (Urbana-Champaign, IL). The method of ionization is given in parentheses.

Analytical normal phase HPLC was performed on a Hewlett-Packard 1100 Series chromatograph equipped with a diode array detector $(214 \mathrm{~nm}$ and $254 \mathrm{~nm})$. All reactions were carried out under an argon or nitrogen atmosphere employing oven- and flame-dried glassware. All solvents were distilled from appropriate drying agents prior to use. $\mathrm{N}$ methyl imidazole and acetic anhydride were distilled and stored in a Schlenk flask for no more than two weeks prior to use. Intramolecular Baylis-Hillman substrate $\mathbf{1}$ was prepared as reported previously in the literature ${ }^{2}$ as well as by the general procedure described. 
General Procedure for the Preparation of Intramolecular Morita-Baylis-Hillman Substrates $(1,4,6,8,10)$.

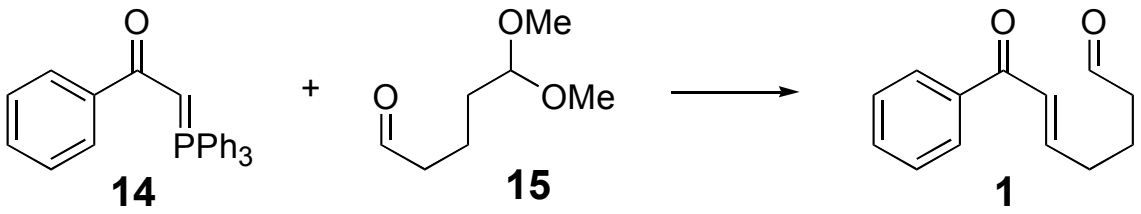

(E)-7-oxo-7-phenylhept-5-enal (1). Phosphorane 14 (9.1 g, $24 \mathrm{mmol})$ was added to a solution of 5,5-dimethoxypentanal ${ }^{4}(15,2.5 \mathrm{~g}, 17 \mathrm{mmol})$ and $\mathrm{CH}_{2} \mathrm{Cl}_{2}(43 \mathrm{~mL})$. The solution was stirred for $24 \mathrm{~h}$ and then concentrated. Flash chromatography of the crude material (hexane-EtOAc, 5:1) yielded the $(E)$ Wittig product in $90 \%$ purity as determined by ${ }^{1} \mathrm{H}$ NMR. This material was then dissolved in THF $(60 \mathrm{~mL})$ and $1 \mathrm{~N} \mathrm{HCl}(20 \mathrm{~mL})$ and stirred at rt. After $2 \mathrm{~h}$, THF was removed in vacuo from the yellow solution and the resultant residue was diluted with $\mathrm{Et}_{2} \mathrm{O}(100 \mathrm{~mL})$ and washed with water $(50 \mathrm{~mL})$, saturated $\mathrm{NaHCO}_{3}(50 \mathrm{ml})$, and brine $(50 \mathrm{~mL})$. The aqueous layers were back extracted with ether $(2 \times 50 \mathrm{~mL})$. The combined organic layers were then dried over $\mathrm{Na}_{2} \mathrm{SO}_{4}$ and concentrated to give a yellow oil. Flash chromatography of the crude material (tolueneEtOAc, 5:1) gave $\mathbf{1}$ as a pale yellow oil $(960 \mathrm{mg}, 4.7 \mathrm{mmol}, 28 \%)$. Compound $\mathbf{1}$, prepared in this manner, is identical to that prepared previously. ${ }^{2}$ Compounds $4, \mathbf{6 , 8}$, and 10 were prepared by analogous methodology.

(E)-7-(4-chlorophenyl)-7-oxohept-5-enal (4).<smiles>O=CCCCCCC(=O)c1ccc(Cl)cc1</smiles>

${ }^{1} \mathbf{H}$ NMR $\left(\mathrm{CDCl}_{3}, 400 \mathrm{MHz}\right) \delta 9.83(\mathrm{~s}, 1 \mathrm{H}), 7.92(\mathrm{~d}, J=8.8 \mathrm{~Hz}, 2 \mathrm{H}), 7.49(\mathrm{~d}, J=8.8 \mathrm{~Hz}$, $2 \mathrm{H}), 7.08(\mathrm{~m}, 1 \mathrm{H}), 6.92(\mathrm{~d}, J=15.6 \mathrm{~Hz}, 1 \mathrm{H}), 2.58(\mathrm{t}, J=7.2 \mathrm{~Hz}, 2 \mathrm{H}), 2.42(\mathrm{q}, J=7.2 \mathrm{~Hz}$, $2 \mathrm{H}), 1.92$ (quintet, $J=7.6 \mathrm{~Hz}, 2 \mathrm{H}) ;{ }^{13} \mathbf{C} \mathbf{~ N M R}\left(\mathrm{CDCl}_{3}, 100 \mathrm{MHz}\right) \delta 201.6,189.3,148.7$, 139.3, 136.2, 130.1, 129.0, 126.2, 43.1, 32.0, 20.6; IR (film, cm-1) 2942, 2823, 2722, $1727,1671,1621,1583,1401,1293,1224,1092,1016 ;$ TLC $\mathrm{R}_{f} 0.31$ (3:1 toluene:EtOAc); Exact mass calcd for $\left[\mathrm{C}_{13} \mathrm{H}_{13} \mathrm{O}_{2} \mathrm{Cl}+\mathrm{H}\right]+$ requires $m / z 237.0682$. Found $237.0693\left(\mathrm{ESI}^{+}\right)$.

(E)-7-(4-bromophenyl)-7-oxohept-5-enal (6).<smiles>O=CCCCC=CC(=O)c1ccc(Br)cc1</smiles>

${ }^{1} \mathbf{H}$ NMR $\left(\mathrm{CDCl}_{3}, 400 \mathrm{MHz}\right) \delta 9.83(\mathrm{~s}, 1 \mathrm{H}), 7.83(\mathrm{~d}, J=8.8 \mathrm{~Hz}, 2 \mathrm{H}), 7.64(\mathrm{~d}, J=8.8 \mathrm{~Hz}$, $2 \mathrm{H}), 7.06(\mathrm{dt}, J=15.2,6.8 \mathrm{~Hz}, 1 \mathrm{H}), 6.89(\mathrm{~d}, J=15.2 \mathrm{~Hz}, 1 \mathrm{H}), 2.56(\mathrm{dt}, J=7.2 \mathrm{~Hz}, 1.2$ $\mathrm{Hz}, 2 \mathrm{H}), 2.40$ (q, $J=6.8 \mathrm{~Hz}, 2 \mathrm{H}), 1.91$ (quintet, $J=7.2 \mathrm{~Hz}, 2 \mathrm{H}) ;{ }^{13} \mathbf{C} \mathbf{~ N M R}\left(\mathrm{CDCl}_{3}, 100\right.$ MHz) $\delta 200.8,188.7,148.1,136.0,131.4,129.6,127.4,125.6,42.8,31.7,20.2$; IR (film, cm-1) 2949, 2886, 2829, 2722, 1721, 1671, 1620, 1583, 1400, 1073, 1010; TLC R $\mathrm{R}_{f} 0.36$ 
(3:1 toluene:EtOAc); Exact mass calcd for $\left[\mathrm{C}_{13} \mathrm{H}_{13} \mathrm{O}_{2} \mathrm{Br}+\mathrm{H}\right]+$ requires $m / z 281.0177$. Found $281.0188\left(\mathrm{ESI}^{+}\right)$.

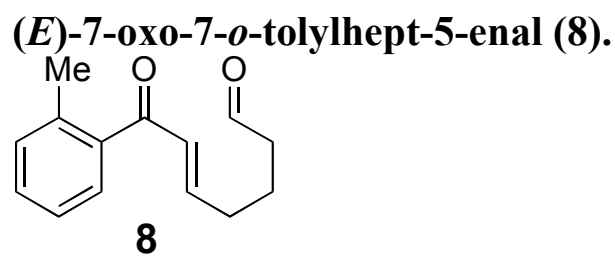

${ }^{1} \mathbf{H}$ NMR $\left(\mathrm{CDCl}_{3}, 400 \mathrm{MHz}\right) \delta 9.80(\mathrm{~s}, 1 \mathrm{H}), 7.42-7.35(\mathrm{~m}, 2 \mathrm{H}), 7.30-7.24(\mathrm{~m}, 2 \mathrm{H}), 6.71$ (dt, $J=15.6,6.8 \mathrm{~Hz}, 1 \mathrm{H}), 6.53(\mathrm{~d}, J=16.0 \mathrm{~Hz}, 1 \mathrm{H}), 2.55-2.53(\mathrm{dt}, J=7.2,1.2 \mathrm{~Hz}, 2 \mathrm{H})$, 2.42 (bs, 3H), 2.34 (q, $J=7.2 \mathrm{~Hz}, 2 \mathrm{H}), 1.85$ (quintet, $J=7.6 \mathrm{~Hz}, 2 \mathrm{H}) ;{ }^{13} \mathbf{C ~ N M R}\left(\mathrm{CDCl}_{3}\right.$, $100 \mathrm{MHz}) \delta 201.1,196.1,149.2,138.5,136.6,131.0,130.2,127.8,125.1,43.0,31.8$, 20.4, 20.2; IR (film, cm- ${ }^{1}$ ) 2930, 2829, 2728, 1728, 1652, 1627; TLC $\mathbf{R}_{\boldsymbol{f}} 0.53$ (3:1 toluene:EtOAc); Exact mass calcd for $\left[\mathrm{C}_{14} \mathrm{H}_{16} \mathrm{O}_{2}+\mathrm{H}\right]+$ requires $m / z$ 217.1229. Found $217.1238\left(\mathrm{ESI}^{+}\right)$.

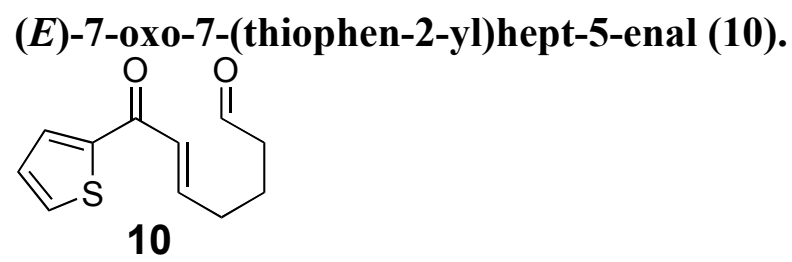

${ }^{1} \mathbf{H}$ NMR $\left(\mathrm{CDCl}_{3}, 400 \mathrm{MHz}\right) \delta 9.82(\mathrm{~s}, 1 \mathrm{H}), 7.77(\mathrm{dd}, J=3.6,0.8 \mathrm{~Hz}, 1 \mathrm{H}), 7.66(\mathrm{dd}, J=$ $4.8,0.8 \mathrm{~Hz}, 1 \mathrm{H}), 7.16(\mathrm{dd}, J=4.8,4.0 \mathrm{~Hz}, 1 \mathrm{H}), 7.07(\mathrm{dt}, J=15.2,7.2 \mathrm{~Hz}, 1 \mathrm{H}), 6.83(\mathrm{~d}, J$ $=15.2 \mathrm{~Hz}, 1 \mathrm{H}), 2.53(\mathrm{dt}, J=7.2,1.2 \mathrm{~Hz}, 2 \mathrm{H}), 2.37$ (q, $J=6.8 \mathrm{~Hz}, 2 \mathrm{H}), 1.88$ (quintet, $J=$ $7.2 \mathrm{~Hz}, 2 \mathrm{H}) ;{ }^{13} \mathbf{C}$ NMR $\left(\mathrm{CDCl}_{3}, 100 \mathrm{MHz}\right) \delta 201.2,181.7,146.9,144.7,133.6,131.7$, 128.0, 126.0, 43.0, 31.7, 20.5; IR (film, cm-1) 3094, 2936, 2829, 2722, 1728, 1659, 1614, 1520, 1420; TLC $\mathbf{R}_{\boldsymbol{f}} 0.46$ (3:1 toluene:EtOAc); Exact mass calcd for $\left[\mathrm{C}_{11} \mathrm{H}_{12} \mathrm{O}_{2} \mathrm{~S}+\mathrm{H}\right]+$ requires $m / z$ 209.0636. Found 209.0634 (ESI $\left.{ }^{+}\right)$.

\section{General Procedure for the Catalytic Intramolecular Morita-Baylis-Hillman Reactions.}

Pipecolinic acid (14.2 mg, $0.11 \mathrm{mmol})$, water $(233 \mu \mathrm{L})$, THF $(659 \mu \mathrm{L})$, and NMI $(41 \mu \mathrm{L}$ of a $1.37 \mathrm{M}$ solution in THF) were added sequentially to a vessel containing aldehyde 4 (132 $\mathrm{mg}, 0.56 \mathrm{mmol})$. The reaction was stirred at room temperature for 48 hours, whereupon the yellow solution was added to $30 \mathrm{~mL}$ of EtOAc and washed with saturated $\mathrm{NH}_{4} \mathrm{Cl}(20 \mathrm{~mL}), \mathrm{NaHCO}_{3}(20 \mathrm{~mL})$, and brine $(20 \mathrm{~mL})$. The organic layer was dried over $\mathrm{Na}_{2} \mathrm{SO}_{4}$, filtered, and concentrated to afford a pale yellow oil (121 mg, 92\% yield of 5). The product isolated in this manner appears as a single compound with slight impurities manifested by low intensity peaks in the baseline of the ${ }^{1} \mathrm{H}$ NMR spectrum (see figure 1). This material may be purified further by flash chromatography using a gradient eluent 
(toluene:ethyl acetate 100:0 to 0:100) affording $5(74 \mathrm{mg}$ ) as a clear oil in $56 \%$ isolated yield.

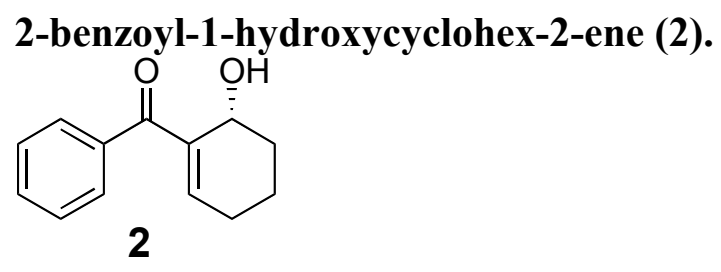

The characterization data for this compound matched that which has previously been reported. $^{2}$

$[\alpha]_{\mathbf{D}}+30\left(\mathrm{c}=1.0, \mathrm{CHCl}_{3}, 80 \%\right.$ ee $)$; Assay of enantiomeric purity: Enantiomers of product were separated by chiral HPLC employing a Chiralcel OD column (Daicel). Conditions: 98:2 hexanes: ethanol; Flow rate $0.75 \mathrm{~mL} / \mathrm{min} ; 18.8 \mathrm{~min}$ (major ent), 22.2 min (minor ent).

The absolute stereochemistry was assigned by Mosher analysis. ${ }^{5}$

\section{Compound 5.}<smiles>O=C(C1=CCCC[C@H]1O)c1ccc(Cl)cc1</smiles>

${ }^{1} \mathbf{H}$ NMR $\left(\mathrm{CDCl}_{3}, 400 \mathrm{MHz}\right) \delta 7.62(\mathrm{~d}, J=8.4 \mathrm{~Hz}, 2 \mathrm{H}), 7.42(\mathrm{~d}, J=8.8 \mathrm{~Hz}, 2 \mathrm{H}), 6.70(\mathrm{t}$, $J=4.4 \mathrm{~Hz}, 1 \mathrm{H}), 4.73(\mathrm{br} \mathrm{s}, 1 \mathrm{H}), 3.38$ (s, 1H), 2.39-2.27 (m, 2H), 1.97-1.85 (m, 3H), 1.68$1.64(\mathrm{~m}, 1 \mathrm{H}) ;{ }^{13} \mathrm{C}$ NMR $\left(\mathrm{CDCl}_{3}, 100 \mathrm{MHz}\right) \delta 197.6,146.7,139.9,138.2,135.9,130.6$, 128.4, 63.9, 29.9, 26.5, 17.5; IR (film, $\mathrm{cm}^{-1}$ ) 3440, 2936, 2867, 1646, 1583; TLC $\mathbf{R}_{\boldsymbol{f}}$ 0.37 (3:1 toluene:EtOAc); $[\alpha]_{\mathbf{D}}+18\left(\mathrm{c}=1.0, \mathrm{CHCl}_{3}, 79 \%\right.$ ee); Exact mass calcd for $\left[\mathrm{C}_{13} \mathrm{H}_{13} \mathrm{O}_{2} \mathrm{Cl}+\mathrm{Na}\right]+$ requires $\mathrm{m} / \mathrm{z}$ 259.0502. Found $259.0503\left(\mathrm{ESI}^{+}\right)$. Assay of enantiomeric purity: Enantiomers of product were separated by chiral HPLC employing a Chiralcel OJ column (Daicel). Conditions: 98:2 hexanes: ethanol; Flow rate $0.60 \mathrm{~mL} / \mathrm{min}$; $28.3 \mathrm{~min}$ (major ent), $32.7 \mathrm{~min}$ (minor ent).

\section{Compound 7.}<smiles>O=C(C1=CCCC[C@@H]1O)c1ccc(Br)cc1</smiles>

${ }^{1} \mathbf{H}$ NMR $\left(\mathrm{CDCl}_{3}, 400 \mathrm{MHz}\right) \delta 7.59(\mathrm{~d}, J=8.8 \mathrm{~Hz}, 2 \mathrm{H}), 7.53(\mathrm{~d}, J=8.8 \mathrm{~Hz}, 2 \mathrm{H}), 6.70$ (t, $J=4.4 \mathrm{~Hz}, 1 \mathrm{H}), 4.73(\mathrm{br} \mathrm{s}, 1 \mathrm{H}), 3.38(\mathrm{~s}, 1 \mathrm{H}), 2.39-2.22(\mathrm{~m}, 2 \mathrm{H}), 1.96-1.83(\mathrm{~m}, 3 \mathrm{H}), 1.69-$ $1.62(\mathrm{~m}, 1 \mathrm{H}) ;{ }^{13} \mathrm{C} \mathbf{~ N M R}\left(\mathrm{CDCl}_{3}, 100 \mathrm{MHz}\right) \delta 197.7,146.8,139.9,136.4,131.4,130.7$, 126.8, 63.9, 29.8, 26.5, 17.5; IR (film, $\left.\mathrm{cm}^{-1}\right)$ 3414, 2936, 2867, 1634; TLC $\mathbf{R}_{f} 0.36$ (3:1 
toluene:EtOAc); $[\alpha]_{\mathbf{D}}+15.4\left(\mathrm{c}=1.0, \mathrm{CHCl}_{3}, 79 \%\right.$ ee); Exact mass calcd for $\left[\mathrm{C}_{13} \mathrm{H}_{13} \mathrm{O}_{2} \mathrm{Br}+\mathrm{Na}\right]+$ requires $\mathrm{m} / z$ 302.9997. Found $302.9996\left(\mathrm{ESI}^{+}\right)$. Assay of enantiomeric purity: Enantiomers of product were separated by chiral HPLC employing a Chiralcel OJ column (Daicel). Conditions: 98:2 hexanes: ethanol; Flow rate $0.60 \mathrm{~mL} / \mathrm{min}$; $30.8 \mathrm{~min}$ (major ent), $35.4 \mathrm{~min}$ (minor ent).

\section{Compound 9.}<smiles>COc1ccccc1C(=O)C1=CCCCC1O</smiles>

${ }_{1}^{1} \mathbf{H}$ NMR $\left(\mathrm{CDCl}_{3}, 400 \mathrm{MHz}\right) \delta 7.32(\mathrm{~m}, 1 \mathrm{H}), 7.21(\mathrm{~m}, 3 \mathrm{H}), 6.6(\mathrm{t}, J=4.0 \mathrm{~Hz}, 1 \mathrm{H}), 4.78$ (br s, 1H), 3.52 (br s, 1H), 2.30 (s, 3H), 2.34-2.15 (m, 2H), 1.93-1.78 (m, 3H), 1.66-1.58 $(\mathrm{m}, 1 \mathrm{H}) ;{ }^{13} \mathrm{C}$ NMR $\left(\mathrm{CDCl}_{3}, 100 \mathrm{MHz}\right) \delta 201.3,148.8,141.4,138.2,135.8,130.6,129.6$, 127.6, 124.9, 63.5, 29.9, 26.7, 19.7, 17.8; IR (film, cm-1) 3478, 2943, 2867, 1633; TLC $\mathbf{R}_{\boldsymbol{f}} 0.38$ (3:1 toluene:EtOAc); $[\alpha]_{\mathbf{D}}+4.2\left(\mathrm{c}=1.0, \mathrm{CHCl}_{3}, 51 \%\right.$ ee); Exact mass calcd for $\left[\mathrm{C}_{14} \mathrm{H}_{16} \mathrm{O}_{2}+\mathrm{Na}\right]+$ requires $\mathrm{m} / z$ 239.1048. Found $239.1045\left(\mathrm{ESI}^{+}\right)$; Assay of enantiomeric purity: Enantiomers of product were separated by chiral HPLC employing a Chiralcel OD column (Daicel). Conditions: 98:2 hexanes: ethanol; Flow rate $0.75 \mathrm{~mL} / \mathrm{min}$; $14.2 \mathrm{~min}$ (major ent), $27.6 \mathrm{~min}$ (minor ent).

\section{Compound 11.}<smiles>O=C(C1=CCCCC1O)c1cccs1</smiles>

11

${ }_{1}^{1} \mathbf{H}$ NMR $\left(\mathrm{CDCl}_{3}, 400 \mathrm{MHz}\right) \delta 7.66(\mathrm{dd}, J=4.8 \mathrm{~Hz}, 1.1 \mathrm{~Hz}, 1 \mathrm{H}), 7.62(\mathrm{dd}, J=4.0 \mathrm{~Hz}$, $1.1 \mathrm{~Hz}, 1 \mathrm{H}), 7.12(\mathrm{~m}, 1 \mathrm{H}), 6.95(\mathrm{~m}, 1 \mathrm{H}), 4.68(\mathrm{br} \mathrm{s}, 1 \mathrm{H}), 3.46(\mathrm{br} \mathrm{s}, 1 \mathrm{H}) .2 .42-2.35(\mathrm{~m}$, $1 \mathrm{H}), 2.32-2.23(\mathrm{~m}, 1 \mathrm{H}), 1.96-1.81(\mathrm{~m}, 3 \mathrm{H}), 1.70-1.65(\mathrm{~m}, 1 \mathrm{H}) ;{ }^{13} \mathbf{C} \mathbf{~ N M R}\left(\mathrm{CDCl}_{3}, 100\right.$ MHz) $\delta 189.8,143.2,142.6,139.9,133.4,133.3,127.6,64.1,29.9,26.2,17.4$; IR (film, $\left.\mathrm{cm}^{-1}\right)$ 3440, 2936, 2867, 1621; TLC $\mathbf{R}_{\boldsymbol{f}} 0.32$ (3:1 Toluene:EtOAc); $[\alpha]_{\mathbf{D}}+37(\mathrm{c}=1.0$, $\mathrm{CHCl}_{3}, 74 \%$ ee); Exact mass calcd for $\left[\mathrm{C}_{11} \mathrm{H}_{12} \mathrm{O}_{2} \mathrm{~S}+\mathrm{Na}\right]+$ requires $\mathrm{m} / z$ 231.0456. Found $231.0459\left(\mathrm{ESI}^{+}\right)$. Assay of enantiomeric purity: Enantiomers of product were separated by chiral HPLC employing a Chiralcel OD column (Daicel). Conditions: 95:5 hexanes: ethanol; Flow rate $0.60 \mathrm{~mL} / \mathrm{min} ; 25.7 \mathrm{~min}$ (major ent), $23.2 \mathrm{~min}$ (minor ent). 


\section{Procedure for the Tandem Enantioselective Intramolecular MBH Reaction - Asymmetric Acylation Reaction}

Pipecolinic acid ( $2.6 \mathrm{mg}, 0.02 \mathrm{mmol})$, water $(41 \mu \mathrm{L})$, THF $(94 \mu \mathrm{L})$, and NMI (30 $\mu \mathrm{L}$ of a $0.33 \mathrm{M}$ solution in THF) were added sequentially to a vessel containing aldehyde 1 (20 $\mathrm{mg}, 0.1 \mathrm{mmol})$. The reaction was stirred at room temperature for 48 hours, whereupon the yellow solution was concentrated, transferred to a round bottom flask, and azeotroped with toluene $(5 \times 10 \mathrm{~mL})$. The residue was then dissolved in toluene $(16.8 \mathrm{~mL})$ and peptide $12(7 \mathrm{mg}, 0.005 \mathrm{mmol})$ and acetic anhydride $(37.4 \mu \mathrm{L}, 0.4 \mathrm{mmol})$ were added. The solution was maintained at $\mathrm{rt}$ for $24 \mathrm{~h}$ and then quenched with methanol $(2 \mathrm{~mL})$. After concentration, the residue was dissolved in EtOAc $(30 \mathrm{~mL})$, washed with saturated $\mathrm{NH}_{4} \mathrm{Cl}(20 \mathrm{~mL}), \mathrm{NaHCO}_{3}(20 \mathrm{~mL})$, and brine $(20 \mathrm{~mL})$, and dried $\left(\mathrm{Na}_{2} \mathrm{SO}_{4}\right)$. Concentration gave a yellow oil which was purified by flash chromatography (toluene:ethyl acetate 7:1) affording 2 (9.9 $\mathrm{mg}, 50 \%$ yield, $>98 \%$ ee) as a clear oil.<smiles>CC(=O)OC1CCCC=C1C(=O)c1ccccc1</smiles>

ent-2-Ac

1H NMR $\left(\mathrm{CDCl}_{3}, 400 \mathrm{MHz}\right) \delta 7.70(\mathrm{~d}, J=7.0 \mathrm{~Hz}, 2 \mathrm{H}), 7.53(\mathrm{t}, J=7.3 \mathrm{~Hz}, 1 \mathrm{H}), 7.43(\mathrm{t}$, $J=7.3 \mathrm{~Hz}, 2 \mathrm{H}), 6.72(\mathrm{~m}, 1 \mathrm{H}), 5.99(\mathrm{~m}, 1 \mathrm{H}), 2.46-2.39(\mathrm{~m}, 1 \mathrm{H}), 2.24-2.15(\mathrm{~m}, 1 \mathrm{H}), 2.05-$ 1.98 (overlapping s and $\mathrm{m}, 4 \mathrm{H}), 1.86-1.70(\mathrm{~m}, 3 \mathrm{H}) ;{ }^{13} \mathbf{C}$ NMR $\left(\mathrm{CDCl}_{3}, 100 \mathrm{MHz}\right) \delta$ $195.3,169.8,146.0,137.8,136.7,131.7,129.0,127.9,65.0,28.0,25.8,21.3,17.3$; IR (film, $\mathrm{cm}^{-1}$ ) 2942, 2867, 1733, 1652; TLC $\mathbf{R}_{f} 0.51$ (30\% EtOAc:hexanes); Exact mass calcd for $\left[\mathrm{C}_{15} \mathrm{H}_{16} \mathrm{O}_{3}+\mathrm{Na}\right]+$ requires $m / z$ 267.0997. Found 267.0988 $\left(\mathrm{ESI}^{+}\right)$. Assay of enantiomeric purity: Enantiomers of product were separated by chiral HPLC employing a Chiralcel OD column (Daicel). Conditions: 98:2 hexanes: ethanol; Flow rate $0.75 \mathrm{~mL} / \mathrm{min}$; $15.3 \mathrm{~min}$ (major ent), $16.6 \mathrm{~min}$ (minor ent).<smiles>CC(C)(C)C(Br)Br</smiles>

1H NMR $\left(\mathrm{CDCl}_{3}, 400 \mathrm{MHz}\right) \delta 9.42(\mathrm{~s}, 1 \mathrm{H}), 7.92(\mathrm{t}, J=7.6 \mathrm{~Hz}, 4 \mathrm{H}), 7.58-7.52(\mathrm{~m}, 2 \mathrm{H})$, 7.49-7.43 (m, 4H), 7.08-6.84 (m, 4H), $6.54(\mathrm{t}, J=7.6 \mathrm{~Hz}, 1 \mathrm{H}), 2.51-2.34(\mathrm{~m}, 8 \mathrm{H}), 1.75$ (quintet, $J=7.6 \mathrm{~Hz}, 2 \mathrm{H}) ;{ }^{13} \mathbf{C}$ NMR $\left(\mathrm{CDCl}_{3}, 100 \mathrm{MHz}\right) \delta 194.3,190.2,154.4,147.8$, 147.6, 142.2, 137.6, 132.6, 128.4, 126.4, 32.4, 31.5, 28.7, 27.3, 23.2; IR (film, cm-1) 3056, 2936, 2861, 2722, 1671, 1647, 1620, 1596, 1451, 1287, 1224; TLC $\mathbf{R}_{\boldsymbol{f}} 0.59$ (3:1 toluene:EtOAc); Exact mass calcd for $\left[\mathrm{C}_{26} \mathrm{H}_{26} \mathrm{O}_{3}+\mathrm{H}\right]+$ requires $m / z$ 387.1960. Found $387.1943\left(\mathrm{ESI}^{+}\right)$. 

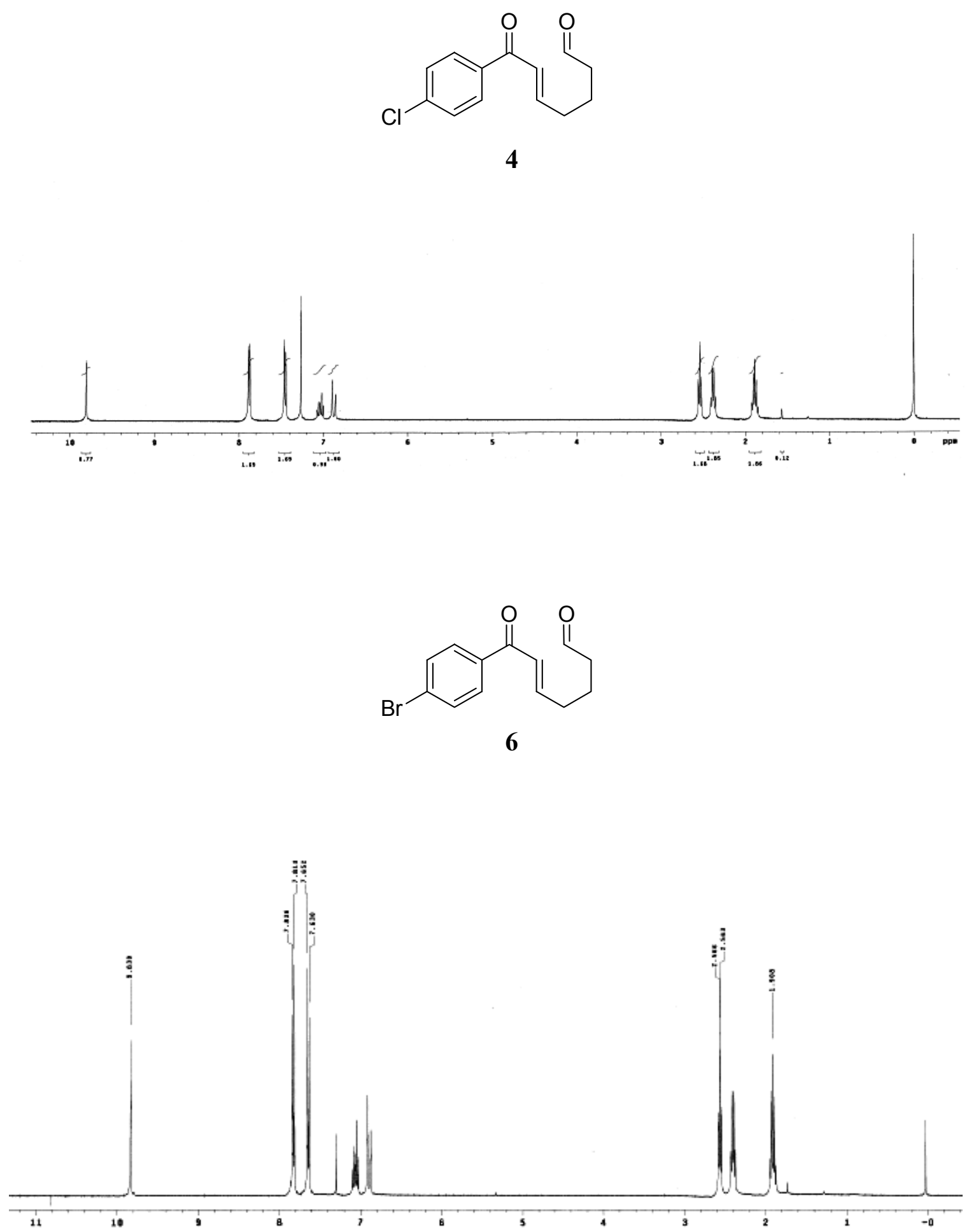


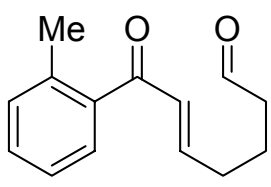

8
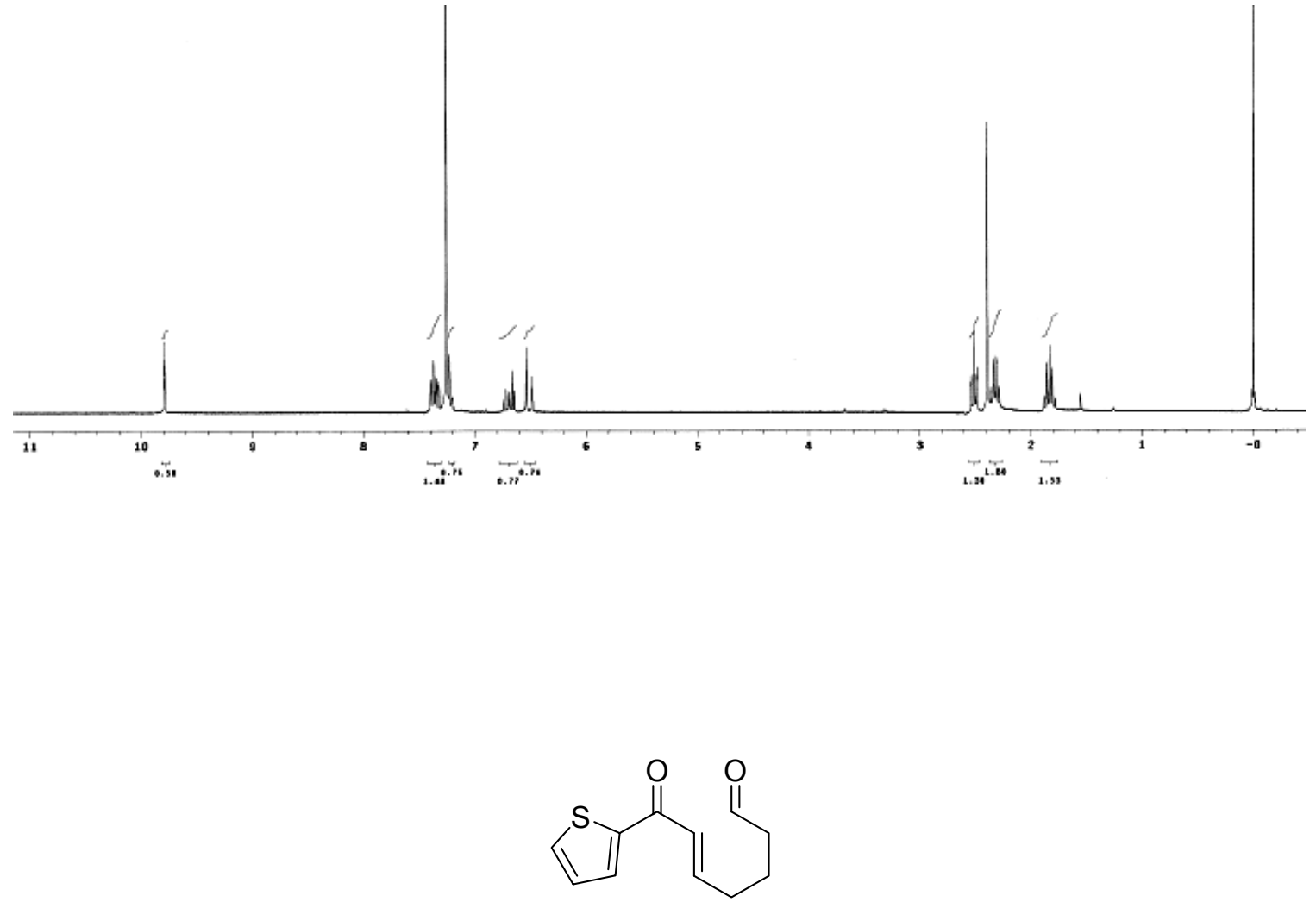

10

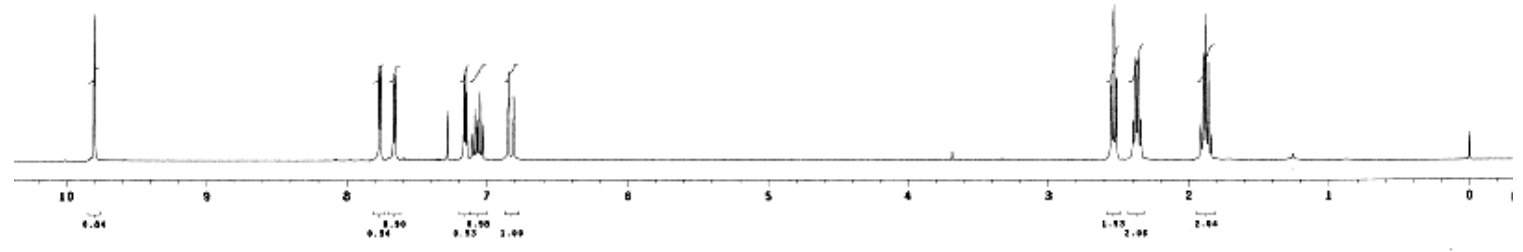


<smiles>O=C(C1=CCCC[C@H]1O)c1ccccc1</smiles>
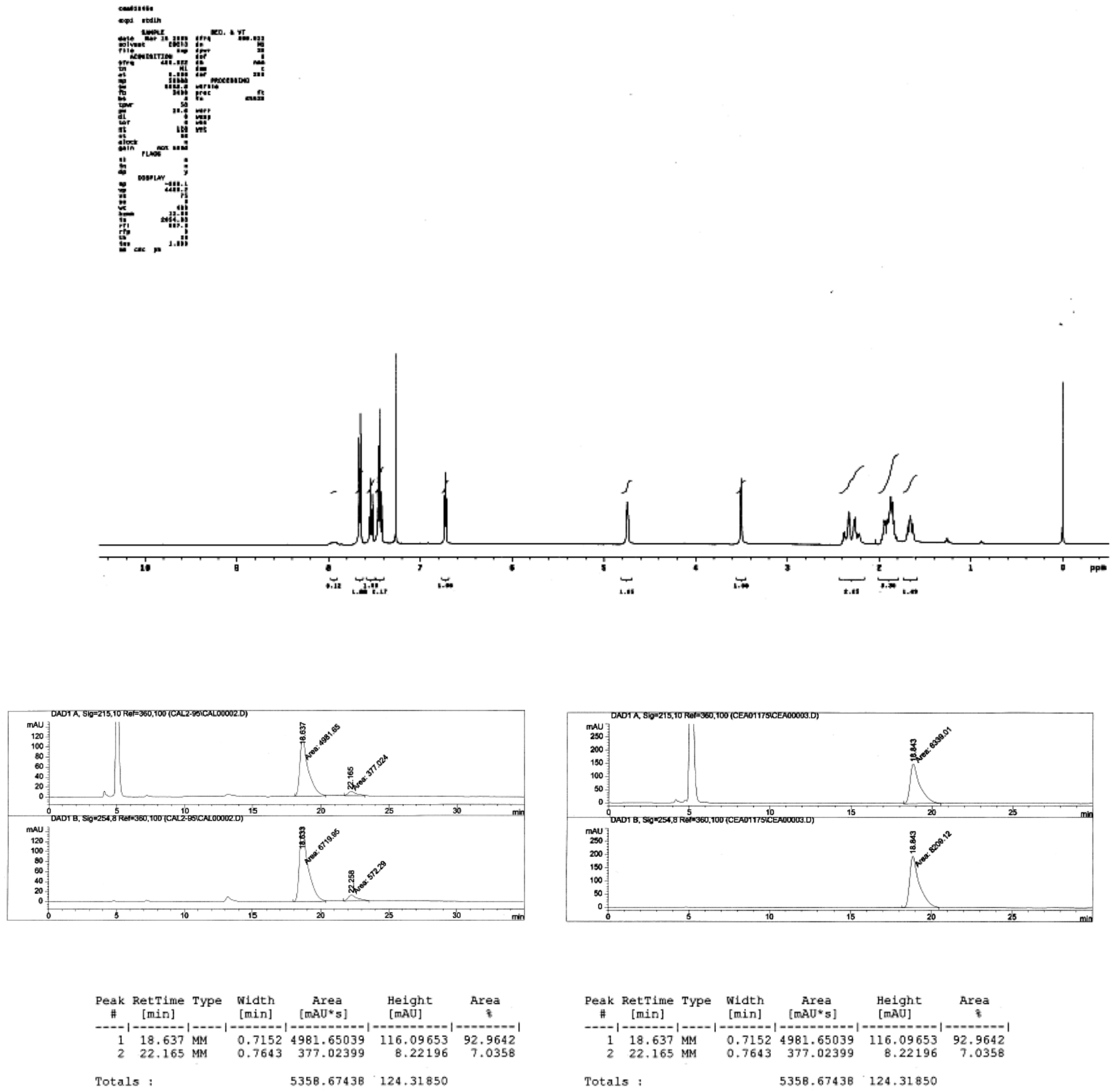

Results obtained with enhanced integrator!

Signal 2: DAD1 B, Sig $=254,8$ Ref $=360,100$

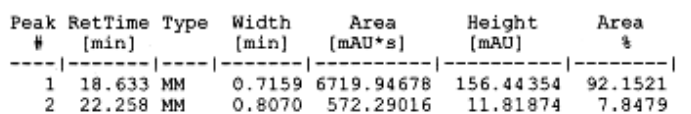

Results obtained with enhanced integrator!

Signal 2: DAD1 B, Sig $=254,8$ Ref $=360,100$

\begin{tabular}{|c|c|c|c|c|c|c|}
\hline Peak & $\begin{array}{l}\text { RetTime } \\
\text { [min] }\end{array}$ & Type & $\begin{array}{l}\text { Width } \\
\text { [min] }\end{array}$ & $\underset{\left[m A U^{*} s\right]}{\operatorname{Ar}]}$ & $\begin{array}{l}\text { Height } \\
\text { [mAU] }\end{array}$ & $\underset{z}{\operatorname{Area}}$ \\
\hline 2 & $\begin{array}{l}18.633 \\
22.258\end{array}$ & MM & $\begin{array}{l}0.7159 \\
0.8070\end{array}$ & $\begin{array}{r}6719.94678 \\
572.29016\end{array}$ & $\begin{array}{r}156.44354 \\
11.81874\end{array}$ & $\begin{array}{r}92.1521 \\
7.8479\end{array}$ \\
\hline
\end{tabular}


<smiles>O=C(C1=CCCC[C@H]1O)c1ccc(Cl)cc1</smiles>
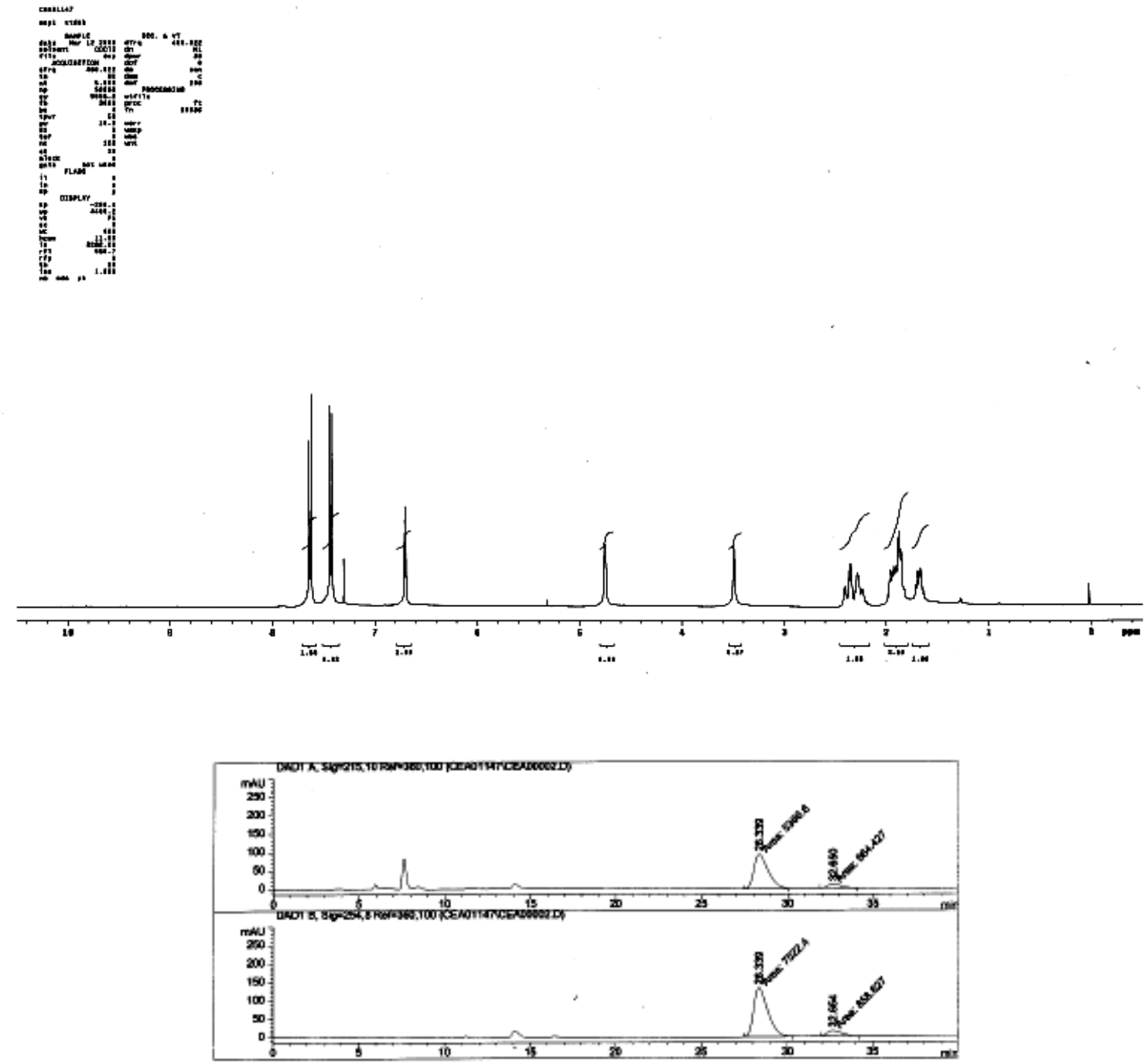

signal 1: DADL $\lambda, 8 L g-215,10$ Pot $-360,100$

\begin{tabular}{|c|c|c|c|c|c|}
\hline Deak & $\begin{array}{l}\text { Metrine Type } \\
\text { [nin] }\end{array}$ & $\begin{array}{l}\text { Wiath } \\
\text { (nin) }\end{array}$ & 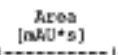 & $\begin{array}{l}\text { Height } \\
\text { [DNoj] }\end{array}$ & $\begin{array}{c}\text { Mres } \\
8\end{array}$ \\
\hline$\frac{1}{2}$ & $\begin{array}{l}28.339 \\
32.650 \mathrm{~m}\end{array}$ & $\begin{array}{l}0.9551 \\
0.9106\end{array}$ & $\begin{array}{r}5366.59717 \\
564.42731\end{array}$ & $\begin{array}{l}93.64401 \\
10.33063\end{array}$ & $\begin{array}{r}90.4835 \\
9.5165\end{array}$ \\
\hline Total & $10:$ & & 5931.02448 & 103.97464 & \\
\hline \multicolumn{6}{|c|}{ Besults obtained with enhenesd integruter! } \\
\hline \multicolumn{6}{|c|}{ s1gnal } \\
\hline Peak & $\begin{array}{l}\text { Retrime type } \\
\text { [nin] }\end{array}$ & $\begin{array}{l}\text { Midth } \\
\text { [nin] }\end{array}$ & $\begin{array}{c}\text { Ares } \\
{\left[n A U^{*} \Sigma\right]}\end{array}$ & $\begin{array}{l}\text { Height } \\
\text { [msiv] }\end{array}$ & Area \\
\hline 1 & $23.339 \mathrm{~km}$ & 0.9440 & T522. 99697 & 132.80659 & 89.7551 \\
\hline 2 & $32.604 \mathrm{Ben}$ & 0.9459 & B58.62701 & 15.12957 & 10.2449 \\
\hline
\end{tabular}


<smiles>O=C(C1=CCCC[C@H]1O)c1ccc(Br)cc1</smiles>

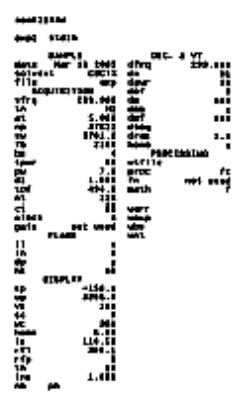
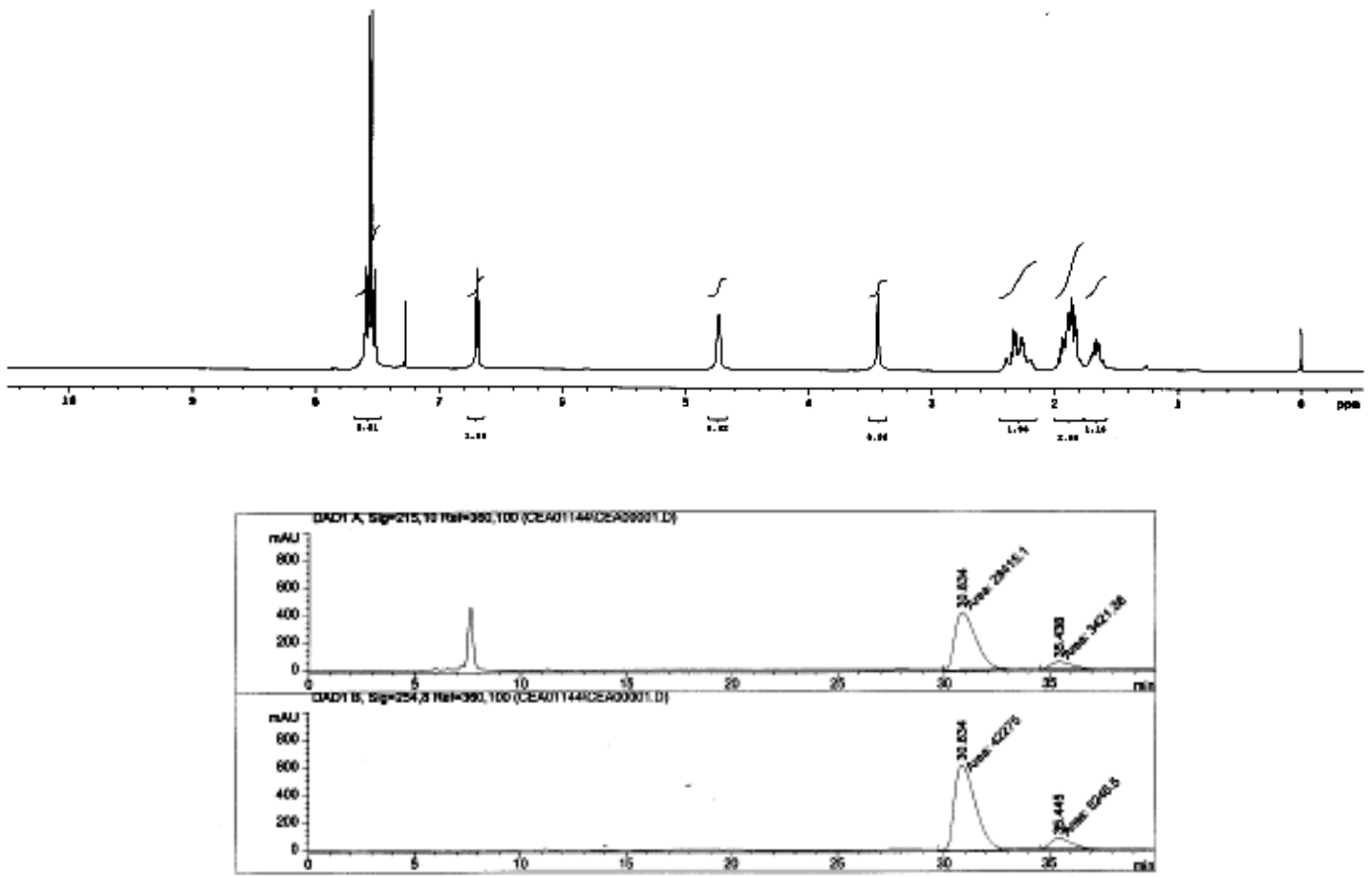

Signal 11 DhD1 he 51g=215,10 Ret=-360,190

\begin{tabular}{|c|c|c|c|c|c|}
\hline Peak & $\begin{array}{l}\text { Fetrise Type } \\
\text { [ain] }\end{array}$ & $\begin{array}{l}\text { Width } \\
\text { [R1n] }\end{array}$ & $\begin{array}{c}\text { Ares } \\
{[m=0]}\end{array}$ & $\begin{array}{l}\text { Height } \\
\text { [mWI] }\end{array}$ & Ares \\
\hline $\begin{array}{l}1 \\
2\end{array}$ & $\begin{array}{l}30.834 \text { ser } \\
35.438 \mathrm{sec}\end{array}$ & $\begin{array}{l}1.1348^{\circ} \\
1.1117\end{array}$ & $\begin{array}{l}2.84151 \mathrm{e} \\
3421.38232\end{array}$ & $\begin{array}{r}417.31009 \\
51.29292\end{array}$ & $\begin{array}{l}89.2532 \\
10.7469\end{array}$ \\
\hline Tatal & L=: & & $3.1836 \mathrm{der}$ & 469.60301 & \\
\hline \multicolumn{6}{|c|}{ Nerults abteined with onhanced integrator! } \\
\hline Denk & $\begin{array}{l}\text { Retinge Typu } \\
\text { [nin] }\end{array}$ & $\begin{array}{c}\text { Width } \\
\text { [zin] }\end{array}$ & $\begin{array}{l}\text { Area } \\
{[n w 0 \cdot a]}\end{array}$ & $\begin{array}{l}\text { Height } \\
\text { [nw] }\end{array}$ & $\underset{8}{\text { Area }}$ \\
\hline$\frac{1}{2}$ & $\begin{array}{l}30.634 \mathrm{vex} \\
35.445 \mathrm{vex}\end{array}$ & $\begin{array}{l}1.1400 \\
1.1284\end{array}$ & $\begin{array}{l}4.2275044 \\
5246.50146\end{array}$ & $\begin{array}{r}618.08105 \\
77.43103\end{array}$ & $\begin{array}{l}\text { a8. } 953) \\
11.0403\end{array}$ \\
\hline
\end{tabular}




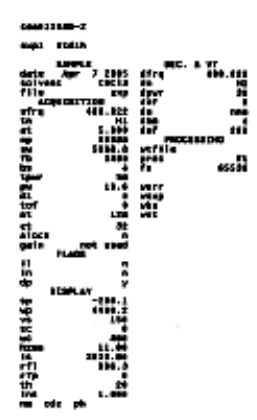<smiles>Cc1ccccc1C(=O)C1=CCCC[C@H]1O</smiles>
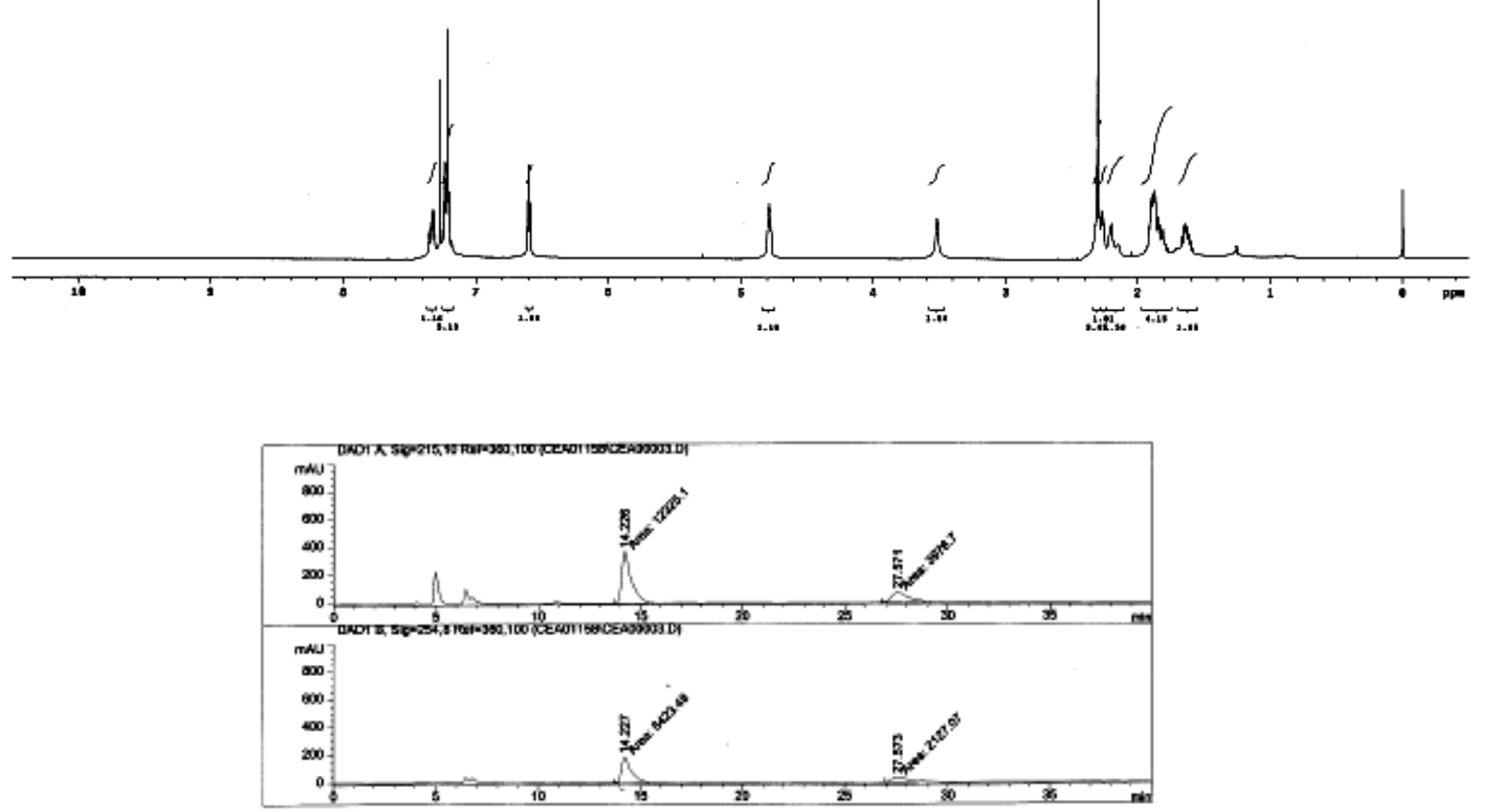

Stgnal 1: DND1 A, 81g-215, 10 Ret $-360,100$

\begin{tabular}{|c|c|c|c|c|c|c|}
\hline reak & $\begin{array}{l}\text { Betrines } \\
\text { [nin] }\end{array}$ & Dree & $\begin{array}{l}\text { Width } \\
\text { (nSI) }\end{array}$ & An: Ares & $\begin{array}{l}\text { Hoight } \\
\text { [nwaj }\end{array}$ & $\stackrel{\text { Aren }}{*}$ \\
\hline$\frac{1}{2}$ & $\begin{array}{l}14.226 \\
23.571\end{array}$ & in & $\begin{array}{l}0.5523 \\
0.9235\end{array}$ & $\begin{array}{l}1.23251 e 4 \\
3976.69873\end{array}$ & $\begin{aligned} 371.93399 \\
71.76760\end{aligned}$ & $\begin{array}{l}T 9.6058 \\
24.3942\end{array}$ \\
\hline notal & $x=$ & & & 1.6301004 & 443.70153 & \\
\hline \multicolumn{7}{|c|}{ Deaults obtained with enhanced integrstor! } \\
\hline Peak & ${ }_{[\min \mid}^{\text {netinge }}$ & Type & $\begin{array}{c}\text { Wideh } \\
{[\min ]}\end{array}$ & $\left.\begin{array}{c}\text { Mres } \\
{\left[\mathrm{a} A \mathrm{U}^{*} \mathrm{E}\right]}\end{array}\right]$ & $\begin{array}{l}\text { Height } \\
\text { [aNo] }\end{array}$ & $\operatorname{sinses}$ \\
\hline$\frac{1}{2}$ & $\begin{array}{l}14.223 \\
23.573\end{array}$ & $\operatorname{lom}_{104}$ & $\begin{array}{l}0.5698 \\
0.9629\end{array}$ & $\begin{array}{l}6423.48047 \\
2127.06934\end{array}$ & $\begin{array}{r}187.90344 \\
36.81874\end{array}$ & $\begin{array}{l}75.1236 \\
24.8764\end{array}$ \\
\hline
\end{tabular}


<smiles>O=C(C1=CCCC[C@@H]1O)c1cccs1</smiles>
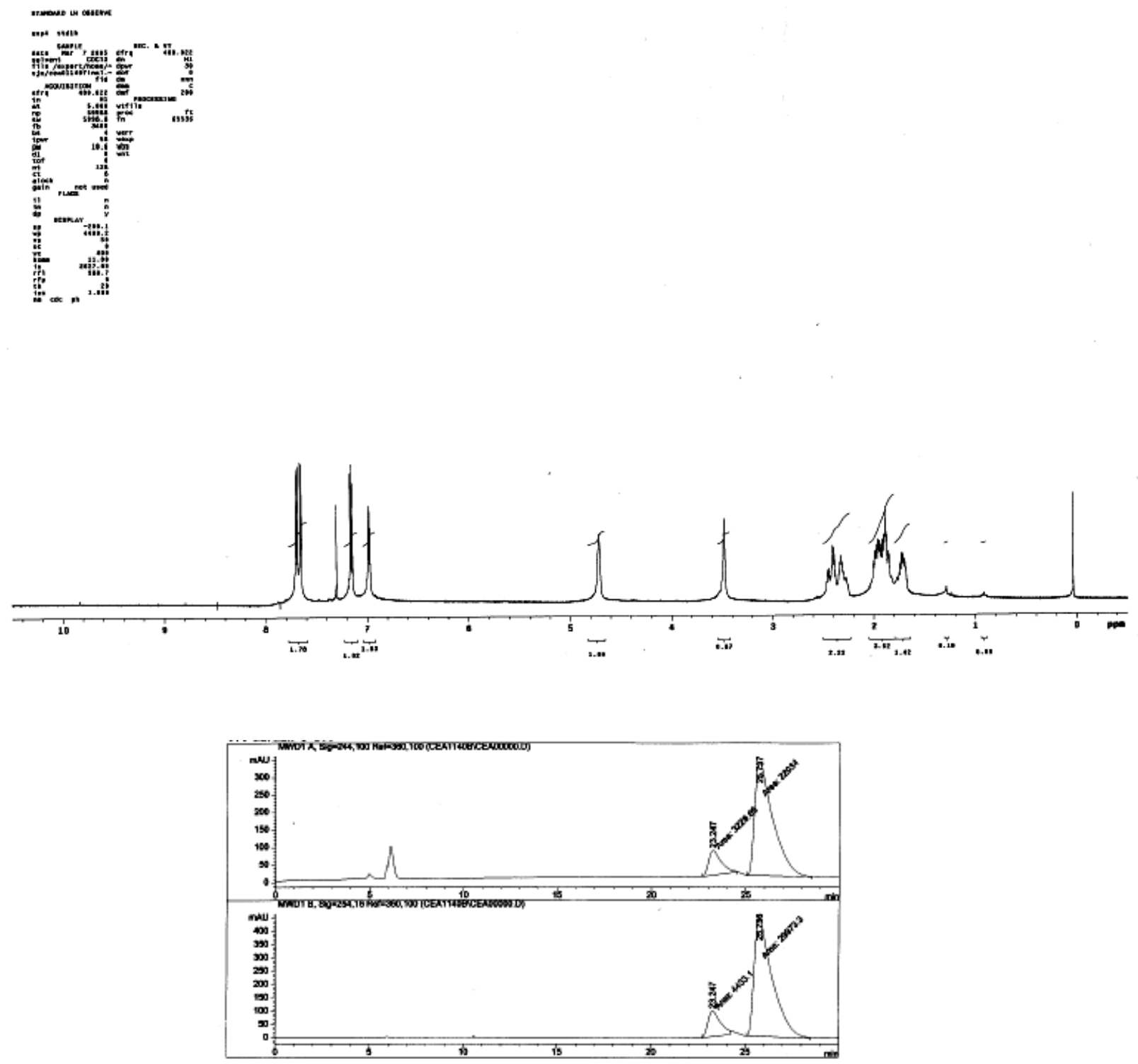

Bignal 1: MND1 A, Biqg-244, 100 Fet $-360,100$

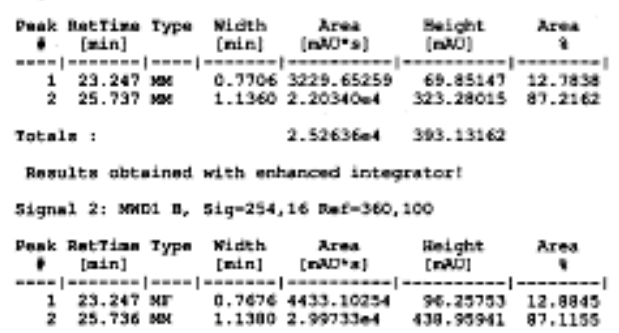


Figure 1. (Compound purity after extractive work-up)<smiles>O=C(C1=CCCCC1O)c1ccc(Br)cc1</smiles>
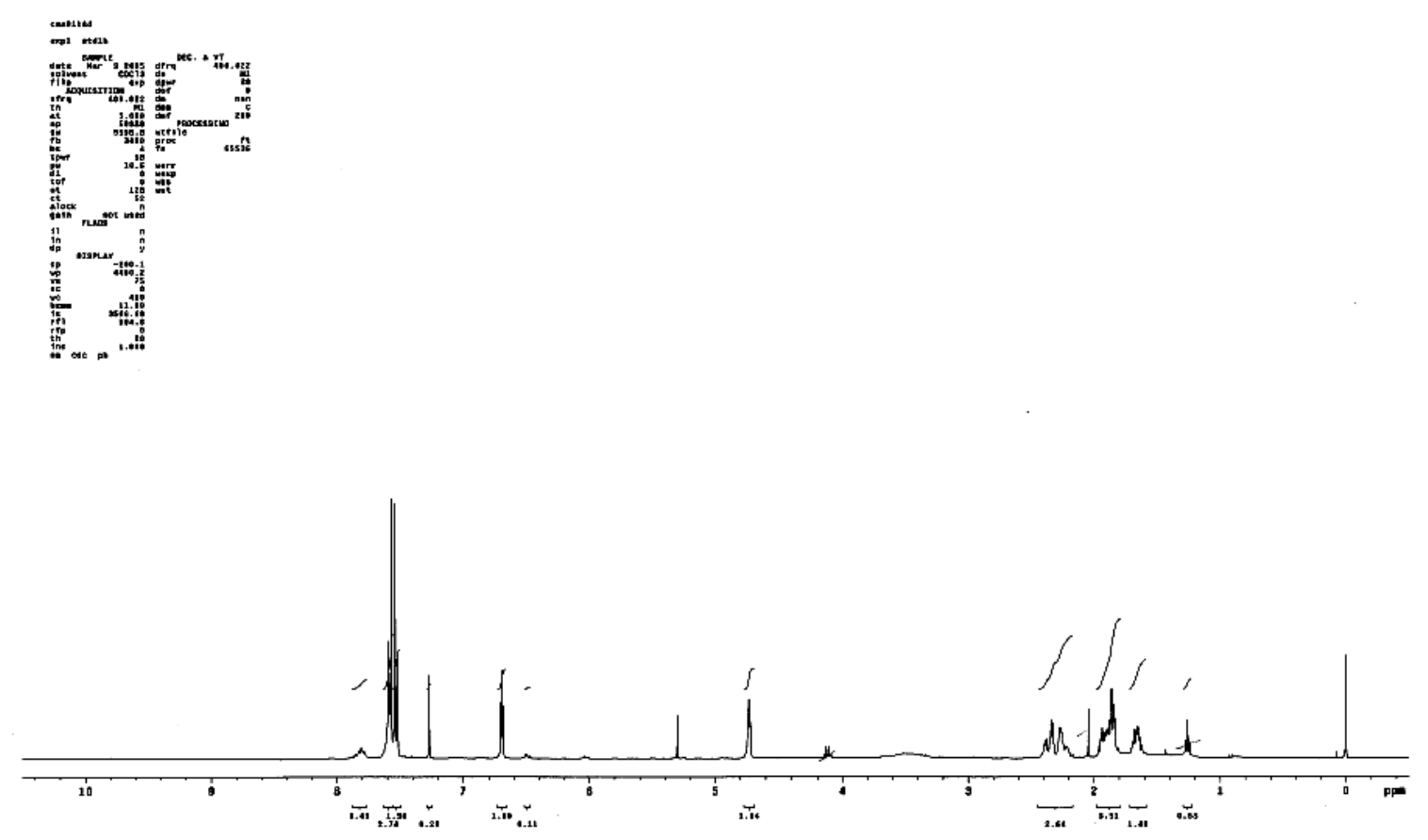<smiles>O=CC(=CCCCC=CC(=O)c1ccccc1)CCC=CC(=O)c1ccccc1</smiles>

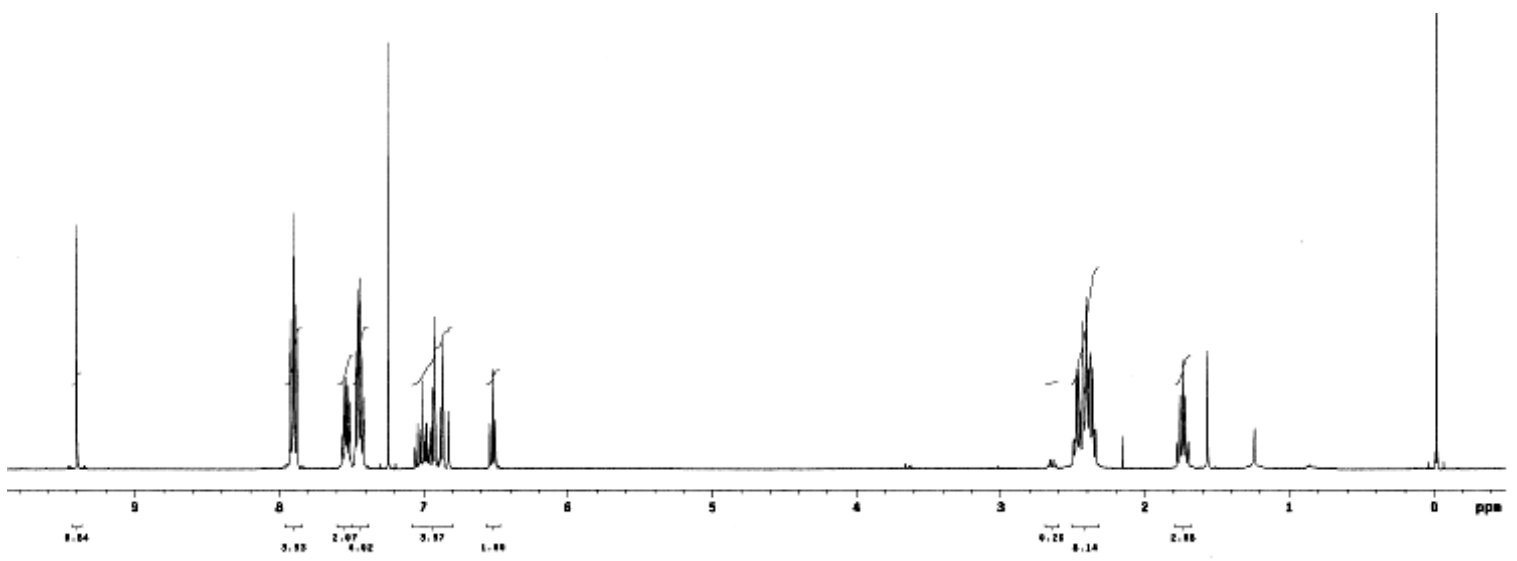




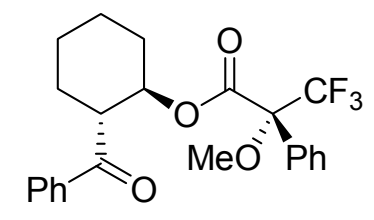

13
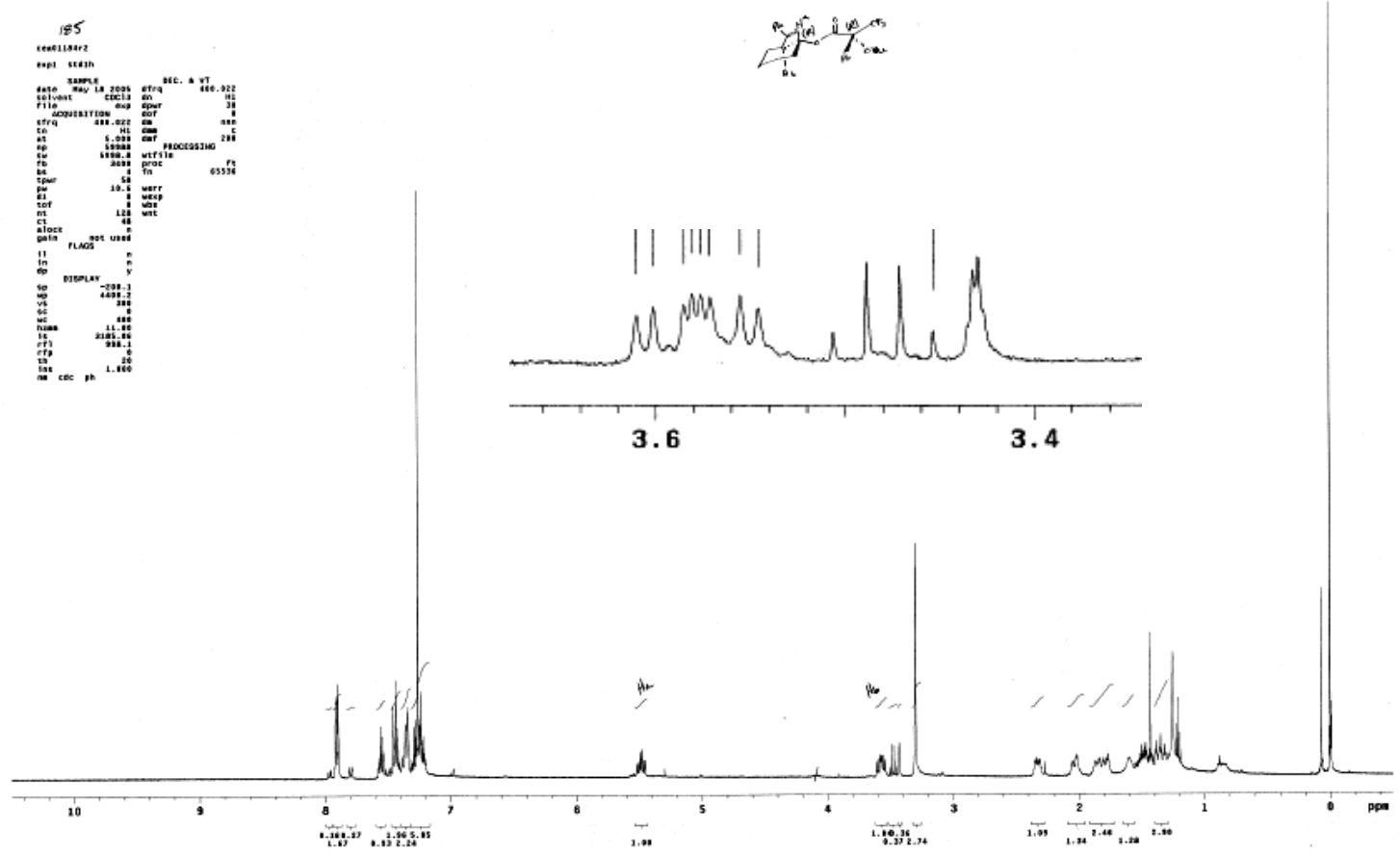


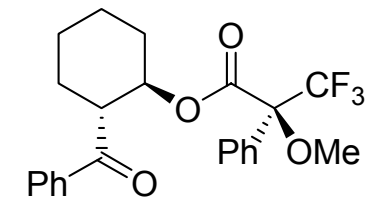

\section{4}

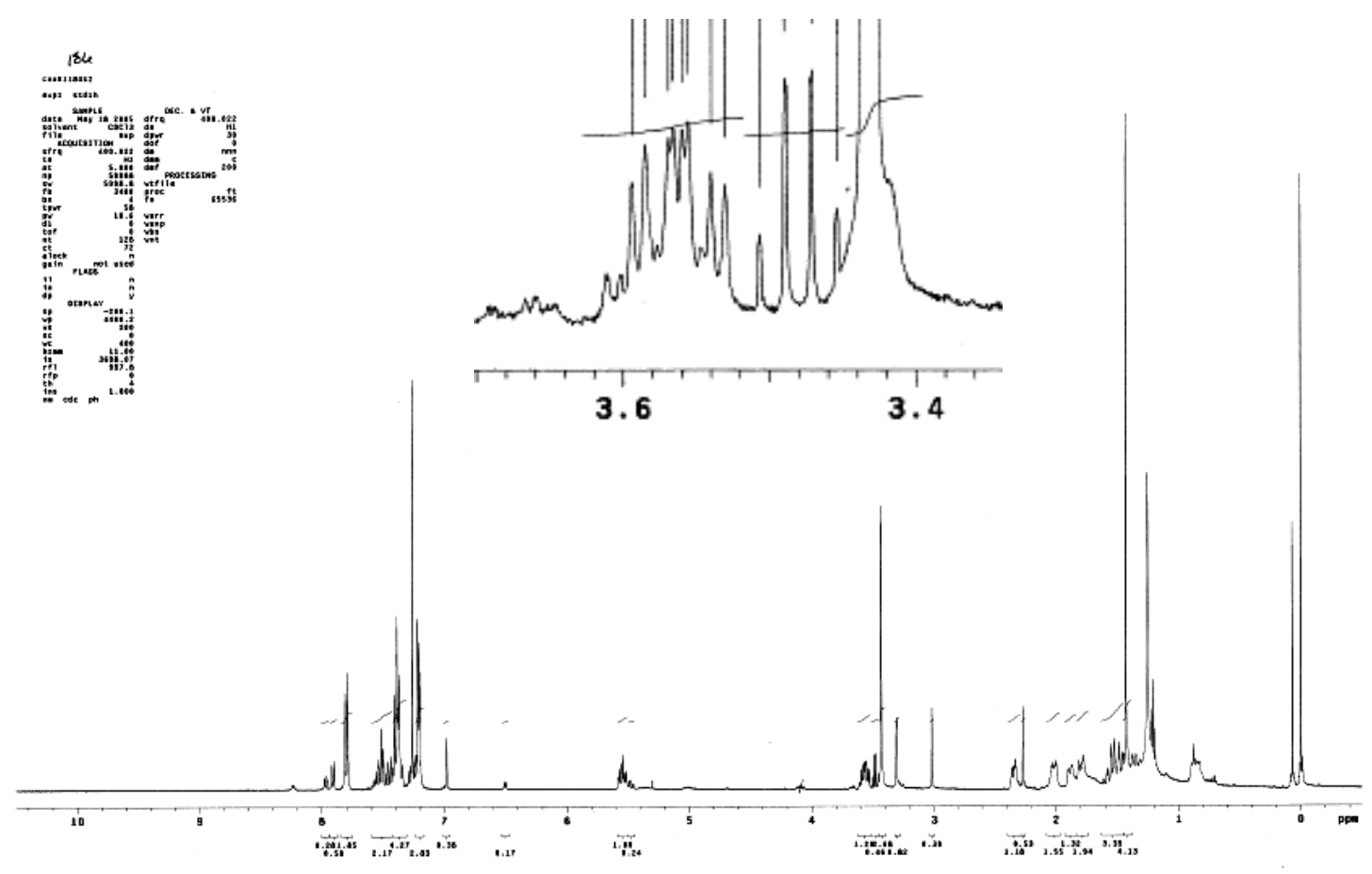

13

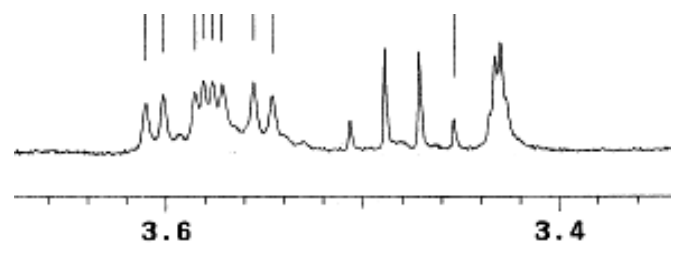

14

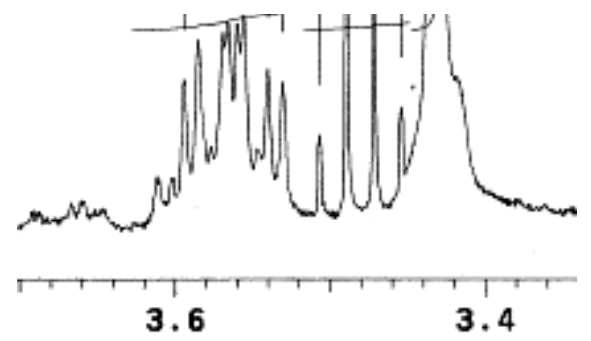


${ }^{1}$ Still, W.C.; Kahn, M.; Mitra, J. J. Org. Chem. 1978, 43, 2923.

2 (a) Montgomery, J; Savchenko, A.V.; Zhao, Y. J. Org. Chem. 1995, 60, 5699-5701. (b) Richards, E.L.; Murphy, P.J.; Dinon, F; Fratucello, S.; Brown, P.M.; Gelbrich, T.; Hursthouse, M.B. Tetrahedron 2001, 57, 7771-7784.

3 (a) Ramirez, F; Dershowitz, S J. Org. Chem. 1957, 22, 41-45. (b) Denney, D.B.; Smith, L.C.; Song, J.; Rossi, C.J.; J. Org. Chem. 1963, 28, 778-780.

${ }^{4}$ Schreiber, S.L.; Claus, R.E.; Reagan, J. Tetrahedron Lett., 1982, 23, 3867-3870.

5 (a) Dale, J.A.; Dull, D.L.; Mosher, H.S J. Org. Chem. 1969, 34, 2543-2549. (b) Dale, J.A.; Mosher, H.S. J. Am. Chem. Soc. 1973, 95, 512-519. (c) Ward, D.E.; Rhee, C.K. Tetrahedron Lett., 1991, 32, 7165-7166. (d) Ohtani, I.; Kusumi, T.; Kashman, Y.; Kakisawa,H. J. Org. Chem. 1991, 56, 1296-1298. 